bronchial responsiveness and occupational asthma. Cross-sectional studies have suggested an excess of asthma symptoms and lung function decline in sawmill workers. The study aims were to measure the incidence of new-onset asthma, to examine longitudinal changes in lung function, and associations with dust exposures.

Methods Associations between dust exposures, asthma symptoms and lung function were studied over three years in a prospective cohort of sawmill workers. Respiratory morbidity was assessed using spirometry and symptom questionnaires, and personal dust exposure was measured, initially on recruitment into the study and then annually for at least two years.

Results We recruited 281 sawmill workers from seven sawmills. Wood dust sampling $(\mathrm{n}=300)$ showed an overall average of $\mathrm{GM}=0.6 \mathrm{mg} / \mathrm{m}^{3}$ (GSD 3.41), range $<0.1$ to $16.9 \mathrm{mg} / \mathrm{m}^{3}$. Asthma symptoms were more common in workers with high exposure compared to the reference group with low exposures $(\mathrm{OR}=1.31,95 \% \mathrm{CI}=0.45-3.83)$. The incidence of new-onset asthma was $4.6 \%$ overall, and $8 \%$ among those with high "dry"dust exposure. In the longitudinal follow-up of workers a clear decline in forced expiratory volume in 1 second $\left(\mathrm{FEV}_{1}\right)$ and maximal mid expiratory flow (MMEF) was evident in the high exposure group, when compared with the non/low-exposed. Although the numbers were small, the decline over the 3 years in both $\mathrm{FEV}_{1}$ and MMEF was statistically significant in the high exposure group.

Conclusions This study confirms that New Zealand sawmill workers generally experience levels of dust exposure below most exposure standards. Notwithstanding this, there is evidence of an increased risk of developing asthma symptoms and lung function decline (of an obstructive nature) over time even at low dust levels, with a suggestion of a dose-response relationship between dust levels and the development of symptoms.

\section{INCIDENCE OF SELF REPORTED ASTHMA OR WHEEZE AMONG WOMEN IN WELDING AND ELECTRICAL TRADES IN THE WHAT-ME STUDY IN CANADA}

J R Beach, Arrandale, Waclawski, Cherry. University of Alberta, Edmonton, Canada

10.1136/oemed-2013-101717.265

Objectives The WHAT-ME study (Women's Health in Apprenticeship Trades-Metalworkers and Electricians) was established because of concerns about risk to the fetus of women welding during pregnancy. Prospective data on work-related health outcomes are also collected. The potential of the study is investigated using 'new-onset asthma or wheeze' as an example.

Methods Women in registered apprenticeships since 2005 in welding, boiler-making, steam fitting/pipefitting ('welders') or electrical trades are invited to join the study. They complete questionnaires on health and exposure at baseline and subsequently every six months. Exposure data are based on the last day at work at each contact, and include information on hazards encountered for each task performed. For the analyses presented here a woman was considered currently working within her trade if working as a welder or electrician at the time of the interview or in the preceding month.

Results To date 496 women have signed up, and recruitment is underway across Canada. The results here are from 385 early recruits (mean age 31.6 years) with completed baseline questionnaires: 220 women, analysed here, have also completed the first (6 month) follow-up questionnaire. At baseline more welders $(28 \%)$ than electricians $(18 \%)$ were current smokers $(\mathrm{p}<0.01)$. Amongst those working since baseline, and who did not initially report asthma/wheeze, 13/95 welders and 3/65 electricians reported asthma/wheeze at 6 months. In a logistic regression analysis, adjusting for smoking, months working in their trade since baseline, and current employment in the trade, welders had an odds ratio of 3.23 (95\%CI $0.85-12.18$ ) for new-onset asthma or wheeze.

Conclusions Female welders appear at higher risk than female electricians of reporting new-onset asthma or wheeze. The continuing recruitment and follow-up of the cohort will provide increasing power for this analysis and information on tasks within trade will help identify recommendations for prevention.

\section{ENDOTOXIN AND GLUCAN EXPOSURE PROTECTS AGAINST ATOPY AND HAY FEVER: A LONGITUDINAL STUDY}

${ }^{1}$ E A J Spierenburg, 'Smit, ${ }^{2}$ Robbe, ${ }^{1}$ Heederik, ${ }^{2} H y l k e m a,{ }^{1}$ Wouters. ${ }^{1}$ Utrecht University, Utrecht, Nederland; '2 University Medical Center, Groningen, Nederland

\subsection{6/oemed-2013-101717.266}

Objectives We previously showed that occupational endotoxin exposure in agricultural workers was associated with wheeze and negatively associated with atopy. We recently completed a 5 "year follow" up of the initial study population. This study aimed to analyse change and persistence in status of atopic sensitizaton, (self reported) allergy, hay fever and wheeze in relation to baseline endotoxin and glucan exposure.

Methods We studied an occupational cohort of 259 Dutch farmers and agricultural workers recruited in 2006 and followed up in 2011. Endotoxin and glucan exposure were assigned based on measurements in a subset of the population and exposure modelling. Allergic sensitisation to common allergens (house dust mite, grass, cat, and dog) was based on serum IgE. Atopy was defined as sensitisation against $\geq$ one common allergens. Self-reported wheeze, allergy and hay fever were determined by questionnaire. Associations between exposure and health outcomes were analysed by multinomial logistic regression using four categories based on presence or absence of the outcome at baseline and at follow-up. Analyses were adjusted for possible confounders age, gender, smoking and farm childhood.

Results Baseline glucan and endotoxin exposure levels were highly correlated $(r>0.9)$. Glucan and endotoxin exposure were negatively associated with persistent reporting of hay fever symptoms (OR 0.58, 95\% CI [0.41-0.82] and 0.69 [0.48$0.98]$ respectively) or atopy (OR 0.7 [0.56-0.90] and 0.74 [0.56-0.98] respectively). Higher endotoxin exposure tended to be negatively associated with persistent self reported allergy and sensitisation against grasspollen (OR 0.84 [0.68-1.02] and 0.79 [0.62-1.02]). Presence of house dust mite-specific IgE or wheeze was not associated with glucan or endotoxin exposure. Changes in outcome status were rare and not clearly associated to exposure.

Conclusions Exposure to both endotoxin and glucan protects from persistent atopic disease. These results could be suggestive of a healthy worker selection. However, a previously performed healthy worker survivor analysis showed no such selection. 